\title{
Business and Human Rights in ASEAN: Lessons From the Palm Oil Sector in Malaysia
}

\author{
Andika Ab. Wahab Institute of Malaysian \& International Studies, Malaysia
}

\begin{abstract}
The release of the United Nations Guiding Principles on Business and Human Rights (UNGP-BHR) in 2011 aims to address gaps in human rights governance by setting a standard and corporate culture of respecting human rights. As part of the state responsibility to implement these guiding principles, some member states of the Association of Southeast Asian Nations (ASEAN) have already embarked preliminary steps towards establishing their respective National Action Plan on Business and Human rights (NAPBHR), while others are still lag behind. Drawing from the palm oil sector's experience in Malaysia, this study aims to provide lessons for ASEAN member states to contemplate when developing their NAPBHR, in particular under Pillar 2 of the UNGP-BHR. In this article, I argue that while some large palm oil companies have shown modest progress in realizing their human rights obligation, challenges emerge in many forms including the lack of leadership, collaboration and ambition to steer and scale up industry transformation on human rights across the supply chain. Equally important, challenges around certification scheme depict that it is not the only solution in persuading respect to human rights. Meaningful values transfer often overlooked in certification practice resulting in typical "ticking the audit box" exercise without understanding principles behind it. As such, the development of NAPBHR among the ASEAN member states should reflect on this reality and challenges.
\end{abstract}

Key words: business and human rights, palm oil, due diligence, compliance, certification

\section{Introduction}

Globalization has brought with it increasing economic interdependence through a rapid expansion of cross-border movement of goods, services, technologies and human capital across the globe. Arguably, such expansion has strengthened trade-related standards as the economic actors compete to provide the best products and services in their respective businesses. While it has benefited the international community on various aspects of life, the globalization and expansion of transnational economic activities have its dark side.

Corporate-related human rights violation has been argued to be one of the critical negative consequences brought by globalization in the context of today's international business. Ruggie in his final report submitted to the United Nations' Human Rights Council (UNHRC) 
highlighted that the root cause of the business and human rights predicament today lies in the governance gaps created by globalization - between the scope and impact of economic forces and actors, and the capacity of societies to manage their adverse consequences. The gaps in governance provide a permissive environment for wrongful acts by unscrupulous companies without adequate reparation (Ruggie, 2008, pp. 3).

In 2011, the United Nations' Human Rights Council (UNHRC) endorsed the United Nations Guiding Principles on Business and Human Rights (UNGP-BHR) - a global framework that aspires to serve as an authoritative focal point to enhance standards and practices with regard to business and human rights so as to achieve socially sustainable globalization. The UNGP-BHR is grounded in recognition of its core general principles, namely (i) States' existing obligations to respect, protect and fulfil human rights and fundamental freedoms (Pillar 1); (ii) the role of business enterprises as specialized organs of society performing specialized functions, required to comply with all applicable laws and to respect human rights (Pillar 2); and (iii) the need for rights and obligations to be matched to appropriate and effective remedies when breached (Pillar 3) (UNHRC, 2011, pp. 1).

In order to implement these guiding principles, the states are expected to develop and enact a National Action Plan on Business and Human Rights (NAPBHR). The NAPBHR is expected to assist the states to identify national priorities, develop concrete policy and regulatory options related to business and human rights.

The Office of the High Commissioner for Human Rights (OHCHR, 2019) reports that there are 21 countries who have already produced their respective NAPBHR. None of the member states of the Association of Southeast Asian Nations (ASEAN) has produced a NAPBHR, but countries such as Thailand, Indonesia and Malaysia have expressed their commitment to developing theirs. The OHCHR (2019) also reports that countries such as the Philippines and Myanmar had earlier indicated their readiness to develop NAPBHR in coming years.

In short, the years 2019 and 2020 are a very crucial period for some ASEAN member states in developing their NAPBHR. While the development process of the NAPBHR would certainly involve businesses as one of the stakeholders, limitations persist due to time, geographical and methodological constraints. As such, the stakeholders' engagement might not be able to fully reflect the real challenges facing businesses dealing with the complex supply chain.

Pillar 2 of the UNGP-BHR stresses the important role of the industry players as specialized organs of society - to comply with all applicable laws and corporate regulations, as well as to initiate their respective commitment and strategy 
to respect human rights beyond legal compliance.

Drawing specifically from the palm oil sector's experience in Malaysia, this study aims to provide lessons for ASEAN member states (including Malaysia) to contemplate when developing their NAPBHR, in particular under Pillar 2 of the UNGP-BHR.

In this article, I rely heavily on publicly available sources comprising companies' annual and sustainability reports, sustainability progress updates, sustainability dashboards and other related sustainability information available in their respective official websites.

\section{Business and Human Rights Development in ASEAN}

Human rights are becoming a more prominent subject in ASEAN. Article $1(7)$ of the ASEAN Charter provides a clear commitment among the ASEAN member states to promote and protect human rights and fundamental freedoms in the region. The establishment of the ASEAN Intergovernmental Commission on Human Rights in 2009 and the proclamation of the ASEAN Human Rights Declaration (AHRD) in 2012 further show that human rights are an important regional agenda.

Amongst the earliest initiative with respect to human rights and business in ASEAN was the conduct of a thematic study on corporate social responsibility (CSR) and human rights initiated by the
ASEAN Intergovernmental Commission on Human Rights (AICHR).

The thematic study reports that though many member states are already in possession of rules and regulations to address potential corporate human rights impacts, general awareness on the nexus between CSR and human rights remains low. The report suggests the AICHR and other ASEAN bodies to work together to develop an ASEAN-wide CSR-human rights guidelines to assist member states to enhance their understanding and corporate practices that are aligned with internationally-recognized standards on human rights.

As the follow up to the publication of AICHR thematic study on CSR and human rights, the AICHR organized a four-day training in Bangkok in November 2017 to exchange views on issues and challenges facing the ASEAN member states and businesses in their respective country in the implementation of UNGP-BHR. At the end of this training, participants reiterated the need for the AICHR to develop a regional framework on business and human rights in the region.

In June 2018, the AICHR collaborated with the UNDP Asia-Pacific and several other international organizations in organizing an interregional dialogue to share good practices among different regional mechanisms and countries from other regions in Bangkok, Thailand. The Thai government representative who officiated the interregional dialogue expressed its 
government strong commitment to expedite the development process of its NAPBHR and subsequently urged other ASEAN member states to do the same.

At the state level, as discussed previously, some ASEAN member states have already committed to develop and publish their respective NAPBHR. In fact, some of them are already in the final stage of its development process. Thailand, for example, has recently circulated its final draft NAPBHR to the public for comment in February 2019 and is projected to publish it by the end of 2019. Similarly, Indonesia has started the process to develop NAPBHR in early 2019 and is also expected to publish it in December 2019. In Malaysia, though the Human Rights Commission of Malaysia (SUHAKAM) had published its strategic framework for Malaysia's NAPBHR in 2015, the government does not have a robust plan for its actual development process.

The OHCHR (2019) reports that Myanmar and the Philippines have taken their preliminary steps towards developing their respective NAPBHR. However, no further details as to how the development process progresses. Other countries such as Brunei Darussalam, Cambodia, Lao PDR, Singapore and Viet Nam do not clearly indicate their intention to develop NAPBHR.

\section{Why Palm Oil in Malaysia, and Why Now?}

Malaysia is uniquely positioned as a Southeast Asia's business hub, attracting more than 5,000 foreign corporations from 40 countries operating their businesses in many key economic sectors including agriculture (Yusof, 2017). In this article, I focus specifically on the palm oil business in Malaysia. The reasons for choosing palm oil business sector in this article are manifold.

First, the palm oil industry is an important source of economic growth and development (Szulczyk, 2013), contributing to Malaysia's annual export revenue between RM60 billion (approximately US\$15 billion) and RM70 billion (US\$ 17.5 billion) (Azman, 2013). Moreover, Malaysia is the second largest producer of palm oil and a global major exporter.

Secondly, after more than a hundred years of its existence, palm oil is still a labour-intensive sector, hiring a half million of workers - the majority of which are foreign labourers (Azman, 2013). Undeniably, the growing demand and expansion of business operations have benefited many pockets including the small farmers, local community and workers. However, as the palm oil business proliferates, so has the alleged human rights harms in the palm oil sector. On this note, it is worth mentioning that for the past few years, an increasing number of watchdogs' reports have documented serious labour exploitation against foreign workers in the palm oil sector in Malaysia. These include a report published by Finnwatch (2014) which monitors the realization of labour rights in the activities of Finnish companies and 
their supply chains, including some Malaysian palm oil companies._This justifies another reason why palm oil business is the focus of this article.

In Malaysia, business conducts are governed by the existing national laws and regulations, which include the prohibition of forced and child labour, respecting customary land and indigenous people rights, compliance to safety and health, implementation of a minimum wage, restriction of excessive working hours, and the enjoyment of the right to association. However, human rights in the business sector in Malaysia focuses much on complying with the right to safety and health, and barely pays attention to other labour and human rights as mentioned above.

Businesses in Malaysia are very much accustomed to the concept of CSR (SUHAKAM, 2015) - a set of voluntary actions companies undertake that goes beyond compliance with the existing laws and regulation. In fact, Malaysia is deemed to be one of the emerging economies that are involved in CSR activity (Thompson \& Zakaria, 2004). As part of their CSR activity, many businesses especially Malaysian public listed companies are engaged in corporate disclosure and publicly reporting their social responsibility activities (Mohd Nasir et al., 2013).

In 2007, the Securities Commission (SC) and Bursa Malaysia began to impose a mandatory requirement for all public listed companies to report their CSR activities (Human Rights Resource Centre,
2013). In addition, the Securities Commission promulgated the Malaysian Code for Corporate Governance and the Bursa Corporate Governance Guide which encourage corporate directors to consider producing sustainability reports that address a company's community involvement activities, provision of equal opportunity and diversity, prohibition of child labour, access to grievance and freedom of association (Human Rights Resource Centre, 2013).

Furthermore in 2014, the government of Malaysia through its regulatory body, Bursa Malaysia, initiated the FTSE4Good Bursa Malaysia Index, which requires companies who wish to be included in the index to achieve the set requirements such as monitoring and reporting companies' commitment on human and labour rights, supply chain labour standards, climate change and countering briber (Nordin et al., 2016).

Despite the presence of sustainability certification standards such as the Roundtable Sustainable Palm Oil (RSPO), the industry's enforcement of human rights standards is weak and insufficient to address human rights harms in the palm oil sector (Varkkey, 2015). Human rights campaigning NGOs such as International and Rainforest Action Network (RAN) have criticized the RSPO for having a little concern for the welfare of palm oil workers, and strongly citing that it is a not reliable certification scheme that could ensure sustainable and responsible palm oil production (Chow \& Ananthalakshmi, 2016). 
In view of the mounting pressure on corporate-related human rights harms and relatively slower progress from the government of Malaysia in relation to having a strong governance structure on business and human rights - SUHAKAM published its Strategic Framework on National Action Plan (NAP) on Business and Human Rights in 2015. The strategic framework aims to support the government to develop a dedicated NAP to guide businesses to respect human rights. However, as of end 2018, the government has yet to adopt such NAP, leaving corporations in Malaysia unregulated of their human rights obligations.

\section{Challenges in the Palm Oil Sector in Malaysia}

Collectively, the palm oil business in Malaysia is expanding rapidly - in response to the rising global market demand. In doing that, they need more lands to be converted to oil palm estates, and for that - they need more workers to plant seeds, grow it and harvest them once matured.

It has been argued that while some large palm oil companies have expressed their policy commitment and modest progress in embracing human rights into their business operations, such development has yet to reach their suppliers - comprising small and medium-sized oil palm players. This section discusses what challenges facing oil palm companies, in particular, the small and medium-sized industry players to replicate the progress on corporate respect to human rights that have been performed by large companies.

\section{Gaps in Legal and Regulatory Infrastructure}

Current legal and regulatory infrastructure in Malaysia does not progress on par with the palm oil business expansion, and their responsibility to respect human rights. Companies are not specifically duty bound to declare their human rights commitment, or to undertake human rights due diligence, and report their progress on a regular basis.

However, public listed palm oil companies are required by the laws and regulations to at least report their corporate social responsibility activities. Some companies listed in the Bursa Malaysia are encouraged to produce sustainability report addressing their community engagement activities and other activities related to the promotion of human rights such as the prohibition of child labour, assurance for freedom of association and equal opportunity.

Nevertheless, such requirements are only imposed to a very small number of businesses as compared to the entire industry players in the palm oil sector. The rest of the companies, in particular, the small and medium-sized enterprises including mills, estates and smallholders are left unregulated specific on their human rights commitment. 


\section{Leadership}

When campaigning NGOs, consumer-based associations and regional organizations like the European Commission (EU) lobbying and advocating for the banning of the palm oil products linked to human rights violations - the target often goes to large and established companies and brands. The small and medium-sized industry players are barely affected though they are part of the supply chain.

Let us go back to the spirit of the UNGP-BHR that says every company, regardless of their size of operation has equal responsibility in upholding and respecting human rights. The next question would be how best such responsibility is to be equally distributed when the small and medium-sized companies have many limitations including lack of resources, capacity and ambition to transform their practices?

This brings me to discuss what should be the role of large and public listed palm oil companies in order to bring their supply chain to collectively align their commitment to respect human rights? And, what has been done by these companies, and what else they may consider undertaking?

In this article, I argue that leadership is necessary for large companies to inspire their suppliers to be part of this human rights transformation journey. Many large companies' human rights commitment such as Sime Darby's Human Rights Charter, or Wilmar's No
Deforestation, No Peat and No Exploitation (NDPE) Policy are ambitious in nature, and sometimes beyond the capability of their suppliers to execute. Many of these large companies are also aware of the barriers hindering their suppliers to comply with their human rights commitment. The companies are also aware that the current legal and policy infrastructures do not guarantee their suppliers could achieve their ambitious human rights commitment.

As such, ambitious and visionary policy commitment as shown by these large companies require strong leadership. Leadership in this sense refers to a far-reaching commitment by large companies to lead and drive industry transformation across its supply chain, and possibly across the palm oil sector.

Initially, each level of suppliers (e.g. mill, estate, fresh fruit bunches dealer, small grower and smallholder) has their equal responsibility when it comes to respecting human right. However, each of them has a different level of resources available, capability and exposure to human rights. As such, the suppliers are not well-equipped and ready to commit to human rights requirements. An easy example such as undertaking human rights due diligence is a resource-intensive and heavy exercise, requiring sufficient understanding of the application of human rights principles into the business' activities.

Hence, the responsibility to lead transformation goes back to the large company's prima facie responsibility to 
raise awareness, train, build capacity and support the implementation of human rights initiatives for their suppliers. With that, it is hoped that the trained suppliers will replicate such responsibility with their respective business partners and contractors.

Large and public-listed companies such as Felda Global Ventures (FGV), Sime Darby Plantation and Wilmar International have been organizing capacity building initiatives for their suppliers including mills and estates supplying oil palm fruits and oils to its owned-mills and other operating facilities. If so, why are there still gaps with respect to human rights responsibility among their suppliers on the ground? And, why many other small and medium-sized palm oil companies still lack human rights policy in place? Why some workers are still getting salary below minimum wage?

\section{Industry Collaboration and Innovation}

There is no easy answer to respond as to why there is still a gap with respect to human rights responsibility among industry players. Potential answers may range from the lack of appetite among small and medium-sized companies to change their practices to the lack of legal obligation to govern companies to do so. This brings me to discuss how, and/or whether industry collaboration and innovation could bring industry players, in all its forms, to play their part to respect human rights in the business sector.

Wilmar International was quoted that "individually, we are one drop, collectively, we are an ocean" (Wilmar International, 2017). Collaboration is not just important for companies to act collectively in addressing emerging issues such as corporate-related human rights violations, but also to transform their business practices aligned with the expected standards through sustained collaboration.

Importantly, collaboration among the palm oil players is needed to address common issues facing the industry. Often industry players face common or industry-wide issues. For example, labour shortage and the hiring of undocumented migrant workers are two common issues and practice facing the palm oil companies. These issues are complex to be resolved by industry players alone as it involves the government's migrant worker policy and regulations. As such, the collaboration between companies is needed to raise such issues for the government's immediate intervention.

Collaboration in the palm oil sector often linked to the multi-stakeholder's group, the RSPO. Other than guiding its member companies to comply to the internationally-recognized standards, the RSPO has an important role to play in spearheading collaboration among its members, their suppliers as well as other third party including civil society and regulators. The RSPO is also expected to serve as an advocacy platform in raising and addressing industry-wide human rights issues such as child labour, forced labour, issues relating to non-payment of wages and bonded labour, discrimination 
and gender inequality at the workplace, restriction of freedom of movement and retention of workers' passports.

Varkkey claims that RSPO has been transforming its role from an organization championing sustainability issues into a supra-national policy organization (Varkkey, 2015, pp. 157).

Does it mean that RSPO is now being an active platform for policy advocacy that could shape and influence global oil palm commodity market? To be fair, this is a question needing a thorough observation and analysis, and responses from its member companies. With respect to human rights, the RSPO deserves appreciation for being able to continuously strengthen its human rights principles. The recently revised RSPO's Principles and Criteria (P\&C) (2018), as endorsed by its Board of Governors on 15 November 2018, have included a commitment to provide a decent living wage (see Criteria 6.2) and respect to the rights of human rights defender (see Criteria 4.1).

While the RSPO has been able to strengthen its human rights commitment under its RSPO P\&C, the lack of incentives and added costs to its members triggered more uncomfortable feeling among its members. In fact, the strengthening of human rights principles and criteria in its certification standards is argued to be risking its members to public scrutiny - in relation to human rights noncompliance. Consequently, as claimed by Varkkey there is on-going speculation that there will be RSPO's members in Malaysia will quit from the group and focus more on nationally-based sustainability standard under the Malaysia Sustainable Palm Oil (MSPO) certification (Varkkey, 2015, pp. 157).

The idea of collaboration is often linked to innovation. Technological advancement has been leveraged well by industry players especially in high-value industries such as communication and electronic industries. The palm oil sector, especially the downstream level such as the processors, traders and consumer brands have been innovating ways through technology to map out and share their traceability data, monitor and report the progress of their human rights activities. Similarly, the oil palm growers and large oil palm companies such as FGV, Sime Darby Plantation and Wilmar International - have begun to collaborate with various non-profit organizations and social partners such as the Verite, Solidaridad, Oxfam Novib and Forest Peoples Programme to innovate the ways they assess human rights impacts, and gather, compile and report their human rights activities.

\section{Going Beyond Certification}

The next question is whether the suppliers comprising the medium-sized mills, estates, and growers further down the supply chains - are truly benefiting from this collaboration and innovation, and replicating it at scale. In my final point, I argue that while sustainability certification standards in particular national standards such the MSPO are getting more support from industry 
players - certification alone is not adequate to guarantee the respect to human rights a reality. While the certification standards have positive impacts, we can no longer afford to gloss over its failures (Poynton, 2015).

The objectives of certifications standards, amongst others, to address the wicked environmental and social issues including human rights violations committed by businesses regardless of their place and size of operation. Certification promises the solution to environmental calamity and social issues facing the global community as a whole. To achieve this vision, millions of dollars have been invested to come up with certification model, auditing methodology and compliance mechanism - let alone money that has been invested in the form of consultation and auditing fees. The result of this - a handful of business operations being certified and are eligible to supply their oil palm products to selected global brands who buy only socalled highly traceable and certified oil.

In reality, nevertheless, truly sustainable and responsible practices even among certified companies are not guaranteed. What more among the small and medium-sized oil palm mills and estates who do not even have a standard on human rights to comply with. For the past few years, a number of large and sustainably-certified companies continue to have been associated with numerous human rights violations. For example, Wilmar International was alleged to have committed to child labour in its own plantations and suppliers in Indonesia in 2017 (Amnesty International, 2016). Two years earlier (in 2015), FGV was alleged of committing forced and bonded labour (AlMahmood, 2015). Another Malaysianbased palm oil conglomerate, Kuala Lumpur-Kepong (KLK) was alleged of mistreating its workers in its palm oil estates in Sumatra and Kalimantan, Indonesia in 2013 (Varkkey, 2015).

Wilmar International, FGV and KLK were among RSPO-certified companies who had been strictly audited and certified against internationallyrecognized sustainability standards including human rights. Having been strictly audited by competent auditors, these companies still cannot excuse themselves from critical issues such as human and labour rights violations.

While certification standards emphasize on documentation, assessment and implementation of the action plan "values" in the certification process are often forgotten. Essentially, human rights are about upholding universal values such as "children should not working in the oil palm estate simply because it may compromise their physical safety, child development and access to education". This is not difficult to understand. However, even until today, no one would be able to guarantee that no children are working and/or assisting their parents without proper guidance and adult's supervision in oil palm estate - especially in East Malaysia.

For values to be effectively shared to all industry players and translated into 
business actions - there must be a constant and meaningful engagement and interface between industry players and human rights experts and institutions. Not to say that such engagement has never occurred before - but the questions of "what motivates such engagement to take place" and "what messages were transmitted to industry players during auditing process" are essential. In short, human rights values need to be meaningfully transferred to industry players, and it is more than just a simple exercise of "ticking the audit boxes".

\section{Conclusion}

Based on the palm oil sector's experience in Malaysia, the gaps in governance are contributed by, and exist in many forms, including the lack of national regulatory and policy frameworks from the side of the States, and lack of expertise, ambition and leadership among industry players to steer industry transformation on human rights.

Consequently, too few of the industry players that have progressed and reached a scale commensurate with the challenges at hand. The greatest challenge is how we could ensure the supply chain, which forms the majority of the industry players are progressing, and at the same time making sure that they are not being excluded from the supply chain just because they do not comply with the sought standards. Excluding a problematic or non-compliance supplier from a pool of supply chain does not guarantee that human rights violations will end. In fact, such practices may prevail, and escalate as they continue their business as usual.

As some ASEAN member states are expecting to produce their respective NAPBHR by the end of 2019, while others are expected to follow suit in the coming years - it is important for the states to reflect the real encounters facing companies dealing with complex supply chains such as in the palm oil sector.

Discussion in this preliminary article provides opportunities for future research and may serve as a source of hypotheses for further critical and quantitative studies on human rights governance, within and outside the palm oil sector. For example, future research may further investigate the aspect of human rights disclosure among public listed companies to better understand strategy or system the companies have in place to manage their human rights impacts. Quantitative research may also be undertaken to measure and analyse human rights impacts the companies have in their own business operations, and their suppliers. Further critical research can be initiated to understand the readiness and real challenges facing suppliers in the palm oil sector to commit and fully comply with the expected standards of human rights.

\section{About the Author}

Andika $\mathrm{Ab}$. Wahab holds a $\mathrm{PhD}$ in Anthropology and International Relations from The National University of Malaysia (UKM), and currently working as a 
Research Fellow with the Institute of Malaysian \& International Studies (IKMAS), UKM. He previously served as a Researcher with the Foreign Ministry of Malaysia, working closely with the ASEAN Secretariat and the ASEAN Intergovernmental Commission on Human Rights (AICHR).

\section{References}

Al-Mahmood, S. Z. (2015, July 26). Palm oil migrant workers tell of abuses on Malaysian plantations. Wall Street Journal. Retrieved from https://www.wsj.com/articles/palm -oil-migrant-workers-tell-ofabuses-on-malaysian-plantations$\underline{1437933321}$

Azman, I. (2013). The effect of labor shortage in the supply and demand of palm oil in Malaysia. Oil Palm Industry Economic Journal 13(2): 15-26.

Chow, E. \& Ananthalakshmi, A. (2016). Palm oil industry watchdog lax on human rights: Critics. Retrieved from

https://www.reuters.com/article/us -palmoil-sustainable-rspo/palmoil-industry-watchdog-lax-onhuman-rights-criticsidUSKBN13P072

Finnwatch. (2014). The law of the jungle: Corporate responsibility of Finnish palm oil purchases. Retrieved from https://www.finnwatch.org/images Lpalmoil.pdf
Human Rights Commission of Malaysia (SUHAKAM). (2015). Strategic framework on a national action plan on business and human rights for Malaysia. Retrieved from https://www.suhakam.org.my/stra tegic-framework-on-a-nationalaction-plan-on-business-andhuman-rights-for-malaysia-2015/

Human Rights Resource Centre. (2013). Business and human rights in ASEAN: A baseline study (Malaysia). Retrieved from http://hrrca.org/wpcontent/uploads/2015/09/Businessand-Human-Rights-in-ASEANBaseline-Study-ebook.pdf

International Amnesty. (2016, March 6). The great palm oil scandal: Labour Abuses Behind Big Brand Names. Retrieved from https://www.amnesty.org.uk/files/t he great palm oil scandal lr.pdf

Mohd Nasir, N. E., Abdul Halim, N. A., Mohd Sallem, N. R., Jasni, N. S. \& Aziz, N. F. (2013). Corporate social responsibility: An overview from Malaysia. Journal of Applied Environmental and Biological Sciences 4(10S): 82-87.

Nordin, R., Ishak, M.K., Shapie, R. Bidin, A. \& Witbroadt, M. A. (2016). Integrating human rights into business: Current initiatives in Malaysia. The Law Review 1: 99-115.

Office of the High Commissioner for Human Rights (OHCHR). (2019). National action plan on business 
and human rights. Retrieved from https://www.ohchr.org/EN/Issues/ Business/Pages/NationalActionPla $\underline{\text { ns.aspx }}$

Poynton, S. (2015, November 6). Beyond Certification: Why sustainability certification is part of the problem. Retrieved from Briefing Coorporate Citizenship: https://ccbriefing.corporatecitizenship.com/2015/11/06/beyond -certification-why-sustainabilitycertification-is-part-of-theproblem/

Roundtable on Sustainable Palm Oil (RSPO). (2018). Principles and criteria $(\mathrm{P} \& \mathrm{C})$ for the production of sustainable palm oil. Retrieved from https://rspo.org/principlesand-criteria-review

Ruggie, J. G. (2008). Protect, respect and remedy: A framework for business and human rights. Innovations Technology Governance Globalization 3(2): 189-212.

Szulczyk, K. R. (2013). The economics of the Malaysian palm oil industry and its biodiesel potential. SSRN Electronic Version (January 2013): 118.

Thompson, P. \& Zakaria, Z. (2004). Corporate social responsibility reporting in Malaysia. Journal of Corporate Citizenship 13(Spring): 125-136.

United Nations' Human Rights Council

\footnotetext{
(UNHRC). (2011). United Nations
}

guiding principles on business and human rights: Implementing the United Nations protect, respect and remedy framework. Retrieved from

https://www.ohchr.org/documents Lpublications/GuidingprinciplesBu sinesshr eN.pdf

Varkkey, H. (2015). The human rights dimension in the revised RSPO principles and criteria. Malaysian Journal of International Relations 3 (December): 153-158.

Wilmar International. (2017). Sustainability Report. Retrieved from http://www.wilmarinternational.com/sustainability/re source-library/

Yusof, A. (2017, September 21). Nestle opens its global procurement hub in Malaysia. New Strait Times. Retrieved from https://www.nst.com.my/business/ 2017/11/306520/nestle-opens-itsglobal-procurement-hubmalaysia\%C2\%A0 